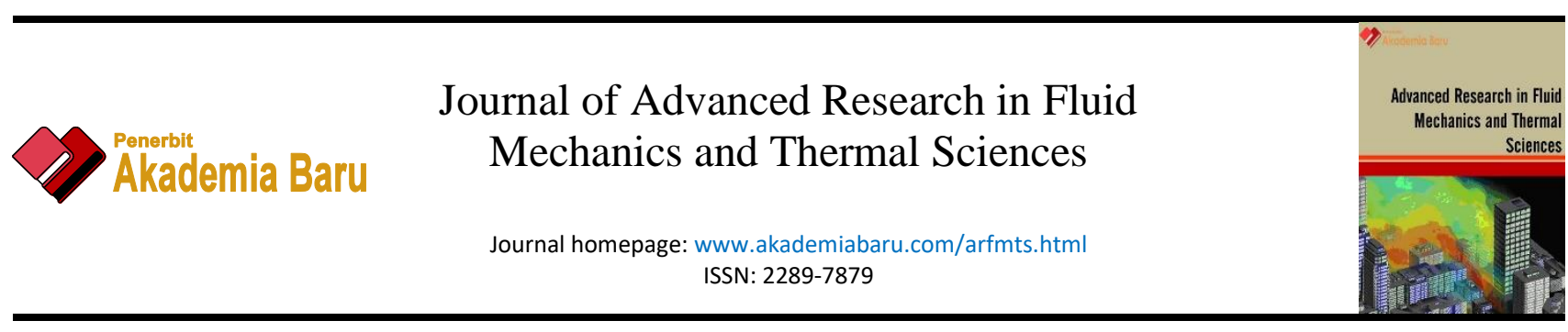

\title{
Aerodynamic Performances of Paper Planes
}

\author{
Noor Iswadi Ismail ${ }^{1}$, Zurriati Mohd $\mathrm{Ali}^{2,}{ }^{*}$, Iskandar Shah Ishak ${ }^{3}$, R.M. Noor ${ }^{1}$, Rosniza Rabilah ${ }^{1}$ \\ Faculty of Mechanical Engineering, Universiti Teknologi MARA, Cawangan Pulau Pinang, 13500 Permatang Pauh, Penang, Malaysia \\ Faculty of Mechanical Engineering, Universiti Teknologi MARA, Cawangan Johor, Kampus Pasir Gudang, 81750 Masai, Johor, Malaysia \\ School of Mechanical Engineering, Faculty of Engineering, Universiti Teknologi Malaysia, 81310 Skudai, Johor, Malaysia
}

ARTICLE INFO

\section{Article history:}

Received 29 January 2020

Received in revised form 17 May 2020

Accepted 17 May 2020

Available online 4 November 2020

Keywords:

Aerodynamics Performances; Paper

Plane; MAV

\section{ABSTRACT}

Paper plane has a high potential to be upgraded as a Micro Air Vehicle (MAV). Due to its simplicity, paper plane offers easier design option compared to the biological inspired designs as shown in recent MAV development. However, researchers have underestimate and overlook the basic aerodynamic performance induced by these paper planes. This is due to its common usage as toys and wide range of paper plane design. Thus, the objective for current work is to analyse and compare the aerodynamics forces and its performance for selected paper plane design known as Glider, Wide Stunt Glider Plane and Stunt plane. A series of CFD simulations on each paper plane was executed by using ANSYS-CFX module. A steady state, incompressible flow Navier-Stokes equation (RANS) combined with Shear Stress Turbulence (SST) model were used in this works to solve flow problem over the paper planes. The analysis is mainly conducted to study and compare the lift coefficient $\left(C_{L}\right)$, drag coefficient $\left(C_{D}\right)$ and aerodynamic efficiency $\left(C_{L} / C_{D}\right)$ performances for each paper planes. The $C_{L}$ results show that the Glider paper plane has managed to produce better $C_{L}$ performances in terms overall $C_{L}$ magnitude, stall angle, wider angle of attack $(\alpha)$ envelope and higher maximum lift coefficient magnitude compared to the other paper plane design. However, Glider paper plane has the least $C_{D}$ distributions by producing at least $14.3 \%$ larger $C_{D}$ magnitude compared to the other plane design at certain $\alpha$ region. Instead, The Wide Stunt has promisingly produced better $C_{D}$ distribution by producing lower $C_{D}$ value compared to the other plane design. Based on $C_{L} / C_{D}$ performance, the Wide Stunt paper plane has produced better $C_{L} / C_{D}$ and maximum aerodynamic efficiency $\left(C_{L} / C_{D \text { max }}\right)$ magnitudes compared to the other design. Wide Stunt paper plane induced at least $6.4 \%$ better $C_{L} / C_{D \text { max }}$ magnitude compared to the other paper plane design. Based on these results, it can be concluded that Wide Stunt paper plane has promising advantages which are very crucial for the paper plane especially during hovering operation, take-off, and landing manoeuvre.

\section{Introduction}

\footnotetext{
* Corresponding author.

E-mail address: zurriatimohdali@uitm.edu.my
}

https://doi.org/10.37934/arfmts.77.1.124131 
Paper planes is seen as a toy figures that gives inspiration in the aeronautical engineering studies which led to a variety of plane design. Indeed, paper plane offer less weight and cost which can be fold based on standard origami technique for any desire shape [1]. The less weight concept parallel with the MAV wing objective which is very crucial to be achieve. Unlike larger systems, MAVs are usually built based of lightweight material stock such as balsa wood [2], injection moulded plastics [3] or even aluminium sheet [4]. However, such materials require substantial processing to fabricate aerodynamic structures [5].

Paper is a biodegradable cellulose fibre sheet which is disposable [6], sturdy and low-cost [5]. Paper consists of a matrix of interlinked cellulose fibers which is a knit structure. The knit structure gives paper good tensile performance and formability with low bulk weight. A low-stiffness hinge can be formed when paper is bent [7]. Even simple bending and forging operations are sufficient to make permanent deformations to the shape of a paper structure, greatly reducing processing cost. At low production input, paper offer an exceptional strength to weight ratio with additional desirable aeroelastic properties [4]. The origami paper plane has been long regarded as flying toys and it can be easily fabricated from paper. Thus, the cellulose material has a bright future to be explored as potential material for disposable MAV option [5].

Paper planes flying in the same Reynolds-number regime as MAV, thus paper plane has a high potential to be upgraded as MAV. Due to its simplicity, paper plane offer easier design option compared to the biological inspired designs as shown in recent MAV development [8-9]. Despite its huge potential through a wide range of origami design [10] and experimental test cycles, researchers have underestimate and overlook the basic performance of lift and drag induced by these paper planes. This is due to its common usage as toys and wide range of paper plane design. Thus, the objective for current work is to analyze the lift and drag performance for the selected paper plane designs. In this work, three different design of paper planes were selected as a basic paper plane design. The design selection was made based on its common usage as paper plane toys and recommendation to be used with PowerUp 3.0 device [11]. Each of paper planes will be analyzed through CFD simulation before the comparison study on lift and drag performance among the plane executed.

\section{Methodology}

\subsection{Paper Plane Design Selection}

There are three different paper plane design have been selected for current works. The selection is made based on its popular usage as paper plane toys and recommendation to be used with PowerUp 3.0 device. PowerUp 3.0 [11] is a device that can remotely control a paper airplane through

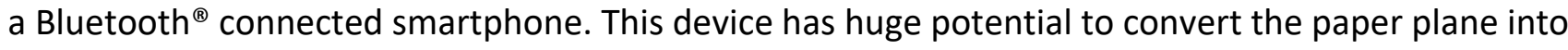
MAV class. The three selected paper plane designs are known as The Glider, Stunt Plane and Wide Stunt Glider paper plane. The CAD drawing of each paper plane design is shown in Figure 1 to Figure 3. The overall wing dimension, aspect ratio and calculated velocity for each paper plane is given in Table 1 . The velocity of each paper plane is determined based on equivalent Reynolds Number at chord, $\operatorname{Re}=100,000$

\subsection{CFD Simulation}

The CFD simulation on each paper plane was executed by using ANSYS-CFX module. The computational air domain was built around the morphing MAV wing, in which the symmetrical condition is exploited by modelling only half of the computational domain. The air domain is built 
surrounding the symmetrical paper plane and sized based on the root chord as shown in Figure 4 . The boundary conditions imposed on the air domain are also shown in Figure 4 . The grid independent test results show that the optimized grid for each paper plane achieved around 300,000 tetrahedrons mesh elements as shown in Figure 5 . The symmetrical wall and side wall are assigned as symmetrical boundary condition and slip surface boundary condition respectively.

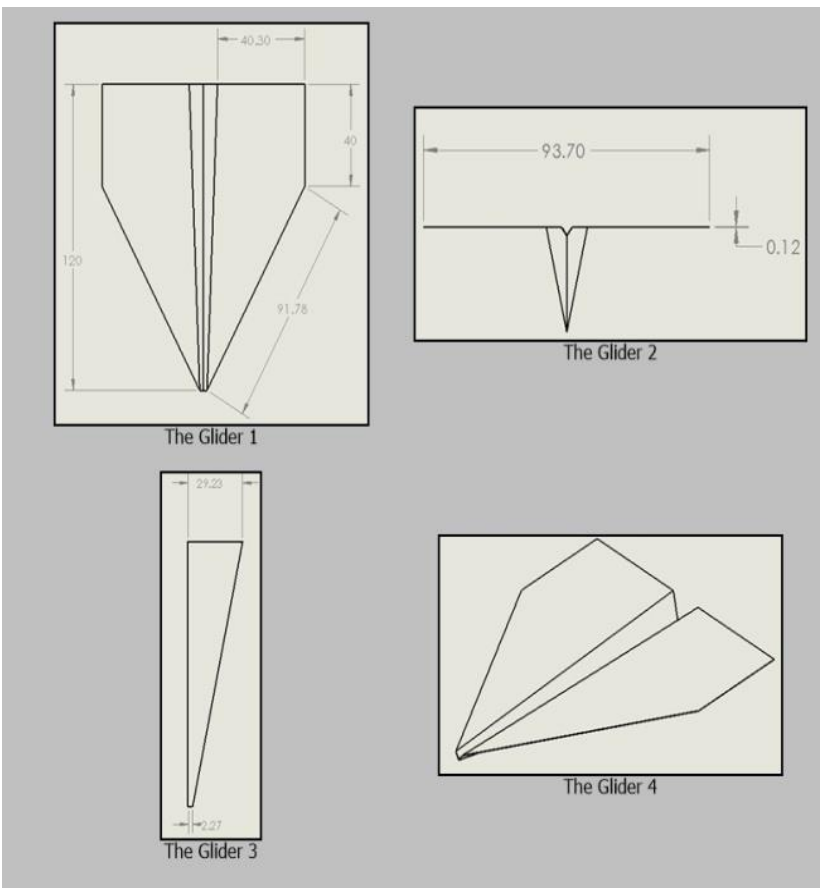

Fig. 1. The Glider paper plane

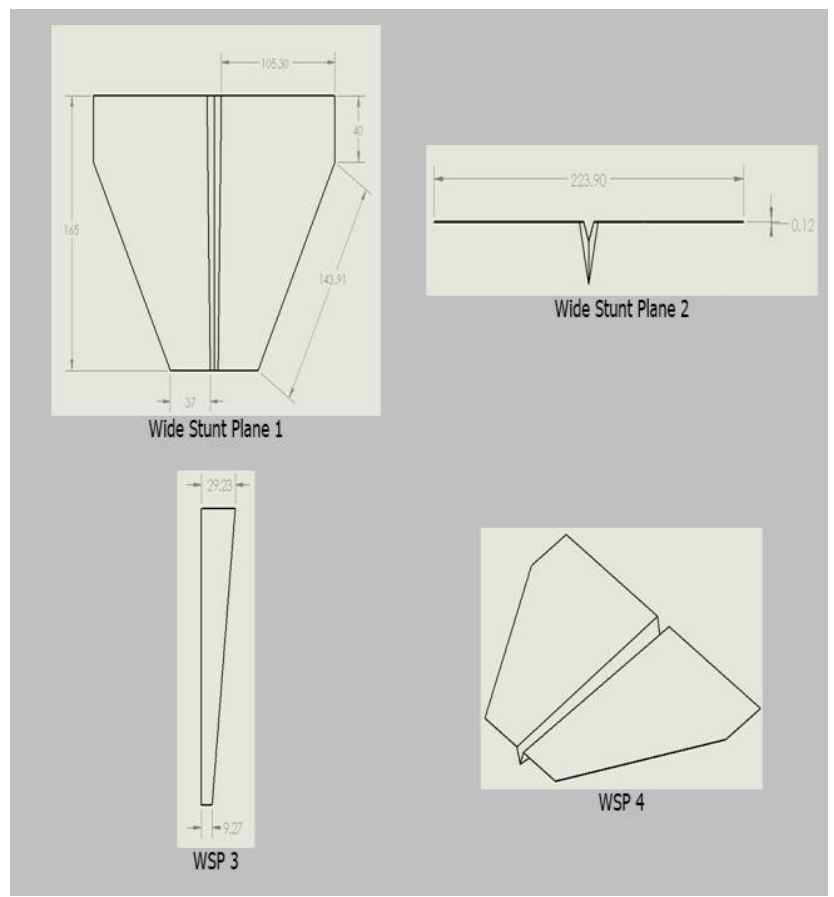

Fig. 2. The Wide Stunt Glider paper plane

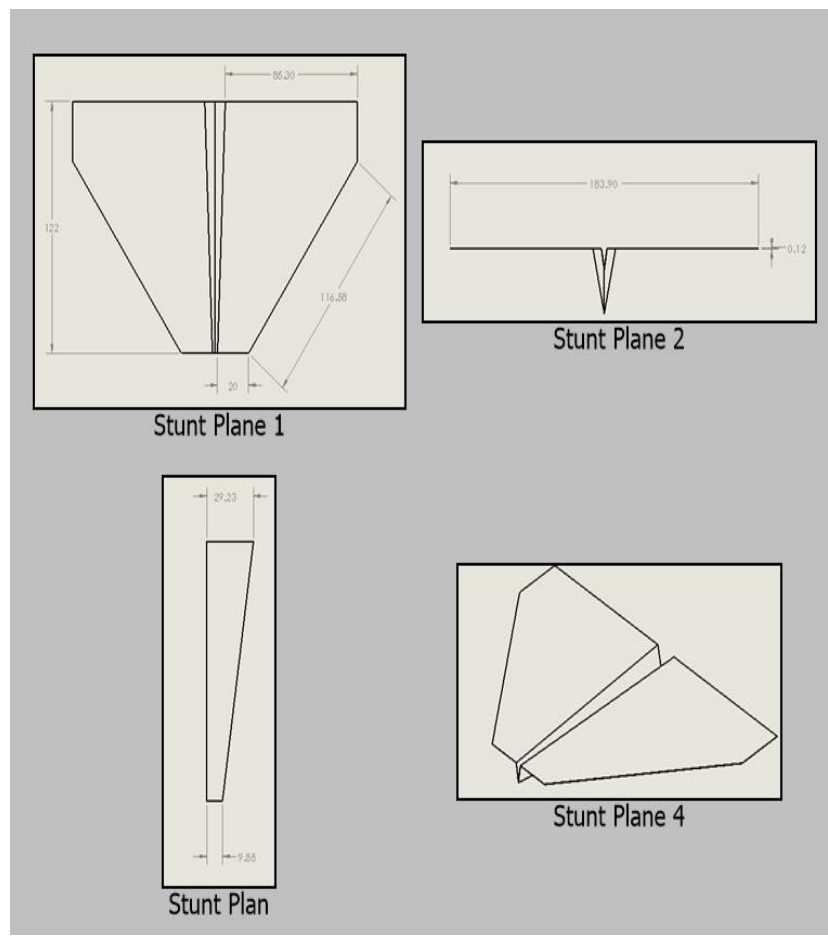

Fig. 3. Stunt Paper plane 
Table 1

The basic dimension of the paper plane designs

\begin{tabular}{llll}
\hline Paper plane & The Glider & Wide Stunt Glider & Stunt Plane \\
\hline Cord length (c) & $121 \mathrm{~mm}$ & $166 \mathrm{~mm}$ & $123 \mathrm{~mm}$ \\
Wing area (S) & $31.3 \mathrm{~cm}^{2}$ & $131.7 \mathrm{~cm}^{2}$ & $74.5 \mathrm{~cm}^{2}$ \\
Aspect ratio (AR) & 2.79 & 3.79 & 3.59 \\
Velocity (U) & $12.5 \mathrm{~m} / \mathrm{s}$ & $8.6 \mathrm{~m} / \mathrm{s}$ & $11.7 \mathrm{~m} / \mathrm{s}$ \\
\hline
\end{tabular}

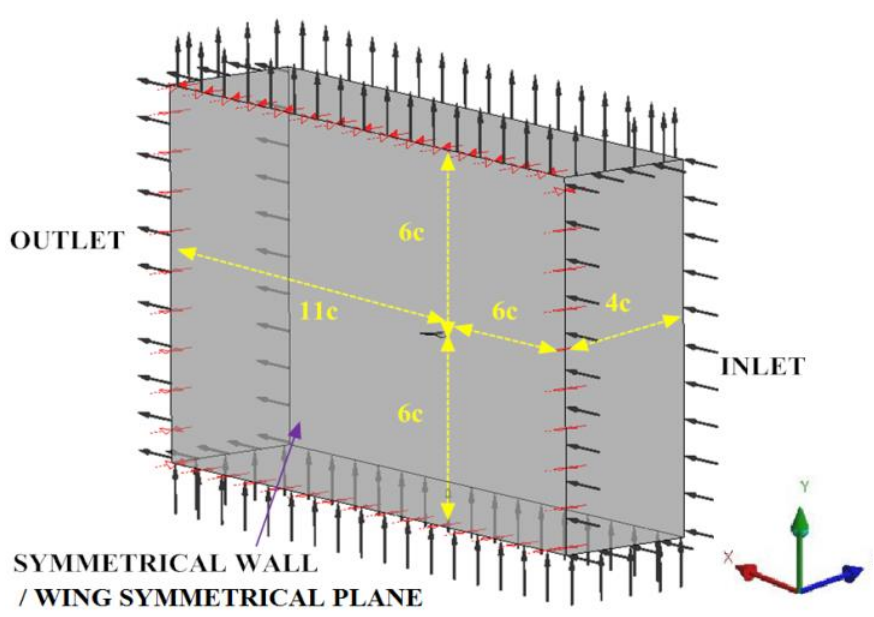

Fig. 4. Air domain sizing and boundary condition imposed on air domain

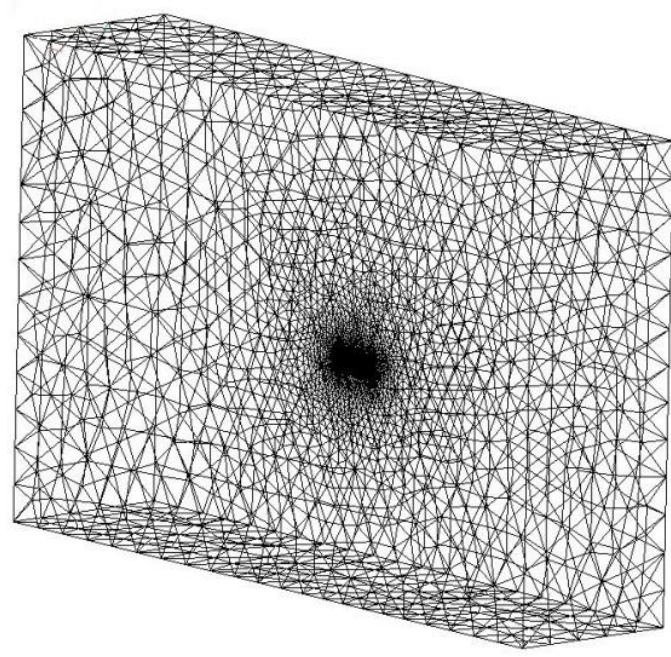

Fig. 5. The optimized grid for each paper plane study

Velocity magnitude (equivalent to $\mathrm{Re}=100,000$ at chord) is specified at the inlet with zero pressure boundary condition is enforced at the outlet. The angle of attack $(\alpha)$ for all paper plane is varied between $-5^{\circ}$ to $40^{\circ}$ with $2^{\circ}$ interval. The wing surface itself is modelled as a non-slip surface. The turbulence intensity is set at $5 \%$ with the automatic wall function was fully employed to solve the viscous effect. A steady state, incompressible flow Navier-Stokes equation (RANS) combined with Shear Stress Turbulence (SST) model were used to solve the turbulence viscosity problems over each paper plane design. The simulation convergence was control based on the magnitude of momentum residual (below $1.0 \times 10^{-5}$ ) and monitoring the value of lift $\left(C_{L}\right)$ and drag $\left(C_{D}\right)$ coefficients.

\section{Results}

\subsection{Lift Coefficient $\left(C_{L}\right)$ Results}

Figure 6 presents the lift coefficient $\left(C_{L}\right)$ results for Glider, Stunt Plane and Wide Stunt Glider paper plane. The results exhibit that each paper plane produce almost similar $C_{L}$ distribution with the increment of $\alpha$. At pre-stall angle (starts from zero lift angle to stall angle), each plane induces almost linear $C_{L}$ distribution up to the maximum lift coefficient magnitude $\left(C_{L \max }\right)$ at stall angle. However, $C_{L}$ magnitude begins to deteriorate with the increment of $\alpha$ after the stall angle $\left(\alpha_{\text {stall }}\right)$.

Based on the $C_{L}$ magnitude, the results show that Stunt Plane shows better $C_{L}$ magnitude compared to the other plane design at $\alpha$ cases between $0^{\circ}$ to $15^{\circ}$. At this $\alpha$ range, the Stunt plane managed to produce at least $4.4 \%$ better $C_{L}$ magnitude compared to the other plane design. However, as the $\alpha$ magnitude increase over $15^{\circ}$, the Stunt plane has lower $C_{L}$ magnitude than the Glider and Wide Stunt Plane. The Glider has produced almost $12 \%$ better $C_{L}$ magnitude than Stunt plane produced. Even, the Wide Stunt plane also managed to produce averagely $4 \%$ better $C_{L}$ magnitude than Stunt plane at $\alpha$ cases over $15^{\circ}$. Analysis on the magnitude of zero lift angle $\left(\alpha_{L_{=0}}\right)$ 
shows that the Glider paper plane produce the lowest $\alpha_{L_{=0}}$ nearly at $-2^{\circ}$. This is followed by the Wide Stunt and Stunt Plane at nearly $\alpha_{L_{=0}}=-1^{\circ}$ and $\alpha_{L_{=0}}=-0.5^{\circ}$, respectively. In terms of $\alpha_{\text {stall }}$ magnitude, the Glider paper plane also induced better stall angle compared to Wide Stunt Plane and Stunt Plane. The Glider paper plane delayed stall at $\alpha_{\text {stall }}=32^{\circ}$ which is about $2^{\circ}$ to $7^{\circ}$ higher than the Wide Stunt Plane $\left(\alpha_{\text {stall }}=30^{\circ}\right)$ and Stunt Plane $\left(\alpha_{\text {stall }}=25^{\circ}\right)$. Based on these $\alpha_{L_{=0}}$ and $\alpha_{\text {stall }}$ performances, the $\alpha$ envelope is determine based on the $\alpha$ range started from the magnitude of $\alpha_{L=0}$ towards $\alpha_{\text {stall }}$. The results clearly exhibited that the Glider paper plane produced better $\alpha$ envelop compared to Stunt Plane and Wide Stunt Glider plane. The $\alpha$ envelop for Glider paper plane is $34^{\circ}$ which is about 9.67\% to $33.3 \%$ better than the $\alpha$ envelop produced by Stunt Plane and Wide Stunt Glider Plane, respectively. The investigation of $C_{L}$ performance continues by evaluating the $C_{L \max }$ performances for each paper plane design. The results show that the Glider paper plane has the highest $C_{L \max }$ magnitude at $C_{\text {Lmax }}=1.246$. This is followed by the Wide Stunt Glider and Stunt paper plane at $C_{\text {Lmax }}=1.136$ and 1.067 , respectively. Thus, the Glider paper plane has at least $9.68 \%$ better $C_{L \max }$ magnitude compared to the other paper plane designs considered in this works. Based on these $C_{L}$ results, one can presumed that the Glider paper plane has the best $C_{L}$ performances among the paper plane designs. Despite of low aspect ratio magnitude (Glider's AR=2.81), the Glider paper plane managed to produce better $C_{L}$ (at $\alpha$ cases over $15^{\circ}$ ), $\alpha_{\text {stall }}$, wider $\alpha$ envelope and higher $C_{\text {Lmax }}$ magnitude.

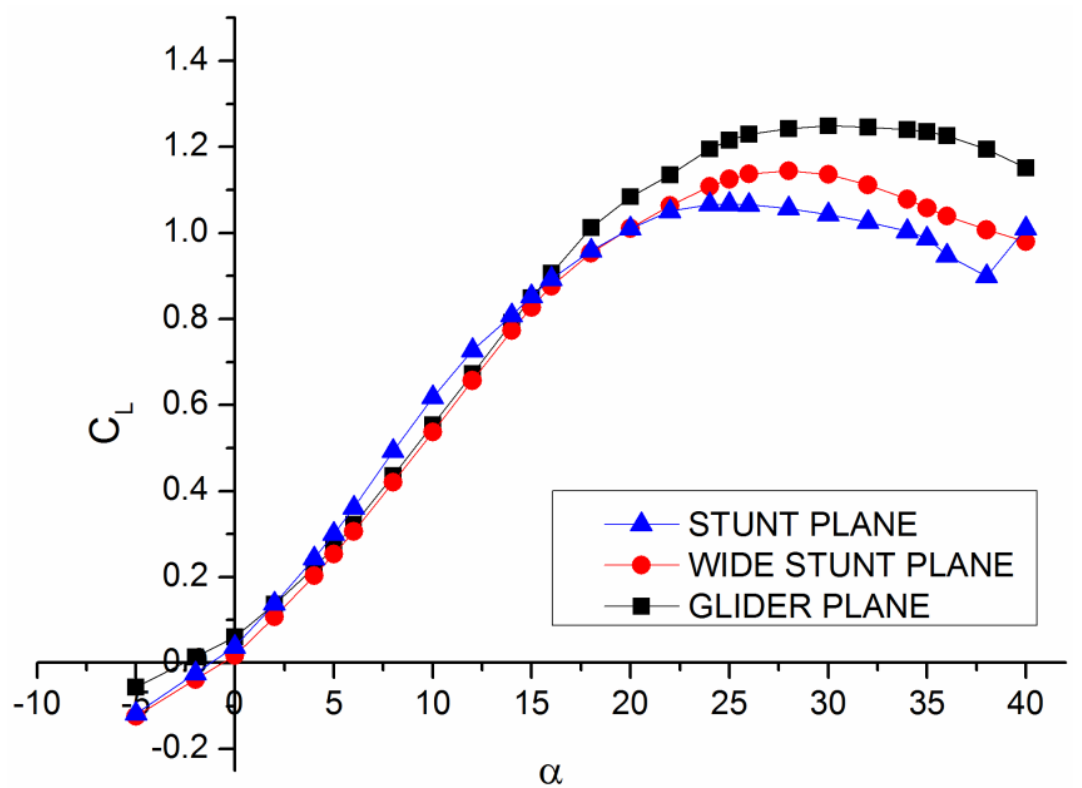

Fig. 6. Lift coefficient $\left(C_{L}\right)$ results for Glider, Stunt Plane and Wide Stunt Glider paper plane

\subsection{Drag Coefficient $\left(C_{D}\right)$ Results}

The Figure 7 presents the drag coefficient $\left(C_{D}\right)$ results for Glider, Stunt Plane and Wide Stunt Glider paper plane. In overall, the results exhibit that each paper plane produce almost similar $C_{D}$ trend towards the increment of $\alpha . C_{D}$ magnitude for all paper plane increase with the $\alpha$ increment. At low $\alpha$ region (between $0^{\circ}$ to $15^{\circ}$ ), the results show that there is no clear difference in $C_{D}$ magnitude among the paper plane. However, The Wide Stunt paper plane managed to produce averagely $5 \%$ lower $C_{D}$ magnitude among the wing at this $\alpha$ region. As the $\alpha$ increase beyond $15^{\circ}$, the difference 
in $C_{D}$ magnitude is more obvious. The Glider paper plane has at least $14.3 \%$ larger $C_{D}$ magnitude compared to the other plane design at this $\alpha$ region. The Stunt paper plane

The investigation on minimum drag $\left(C_{D \text { min }}\right)$ performances reveal that the Wide Stunt Glider paper plane has surprisingly produced the lowest drag magnitude at $C_{D \min }=0.0133\left(\right.$ at $\left.\alpha=0^{\circ}\right)$. This is followed by the Glider and Stunt paper plane which produced $C_{\operatorname{Dmin}}=0.0246$ (at $\alpha=-2^{\circ}$ ) and $0.0185\left(\right.$ at $\left.\alpha=0^{\circ}\right)$, respectively.

Analysis of $C_{D}$ increment between the paper planes was conducted to elucidate the drag performance among the paper planes. The analysis is divided into $2 \alpha$ regions: low $\alpha$ region $\left(\alpha=0^{\circ}\right.$ $15^{\circ}$ ) and high $\alpha$ region $\left(\alpha=15^{\circ}-\alpha_{\text {stall }}\right)$. At low $\alpha$ region, the result shows that the $C_{D}$ magintude for Glider paper plane increse about 31\% for every $2^{\circ} \alpha$ changes. Wide Stunt Glider and Stunt plane produce about $41 \%$ and $36.7 \%$ increment at similar $\alpha$ changes. However, this $C_{D}$ increments were reduced significantly to $12 \%$ (for Glider and Wide Stunt Glider) and 11\% (Stunt) as the angle enter the high $\alpha$ region. Based on these $C_{D}$ results, one can presumed that the Wide Stunt paper plane has more promising $C_{D}$ performances among paper planes. Despite of large $C_{D}$ increments, Wide Stunt has promisingly produced lower $C_{D}$ value (at $\alpha$ region below $15^{\circ}$ ) and lower $C_{D \text { min }}$ magnitude compared to the other plane design.

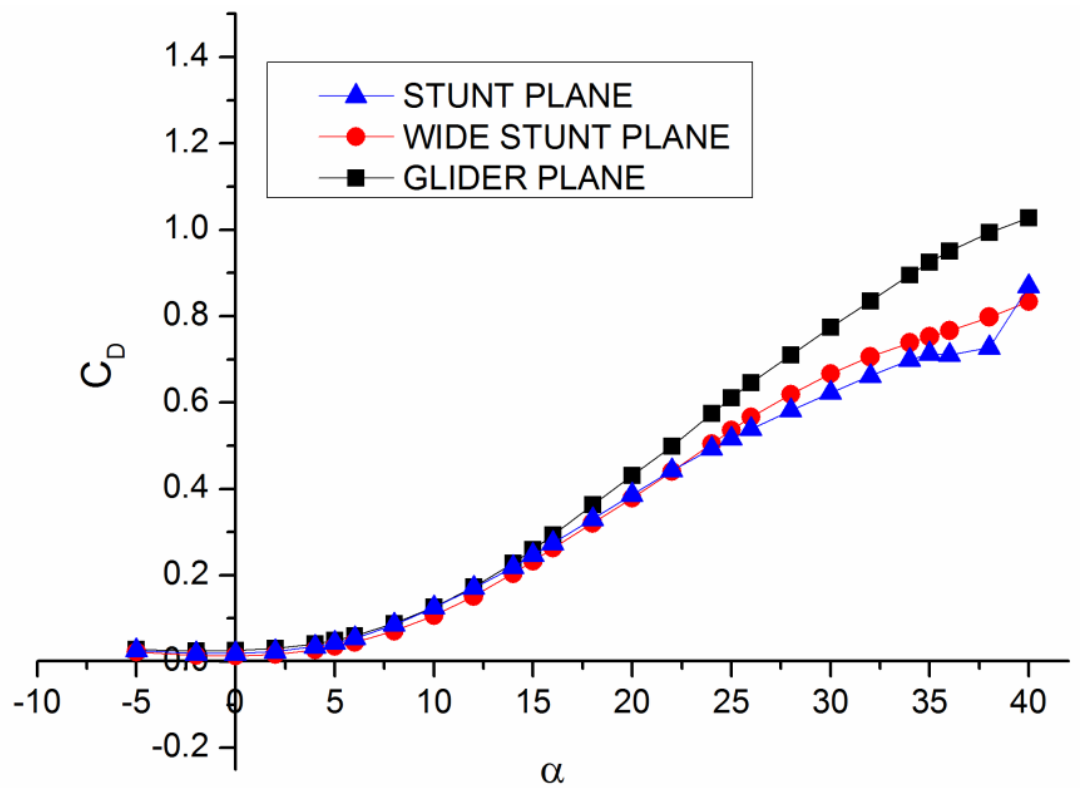

Fig. 7. Drag coefficient $\left(C_{D}\right)$ results for Glider, Stunt Plane and Wide Stunt Glider paper plane

\subsection{Aerodynamic Efficiencies $\left(C_{L} / C_{D}\right)$ Results}

Figure 8 presents the performance of aerodynamic efficiencies $\left(C_{L} / C_{D}\right)$ for each paper plane design considered here. In overall, all paper plane induced almost similar trend of $C_{L} / C_{D}$ curve with the increment of $C_{L}$ magnitude. The magnitude of $C_{L} / C_{D}$ increase almost linearly at early $C_{L}$ increment which is between $C_{L}=-0.056$ to 0.269 which equivalently at $\alpha$ between $-5^{\circ}$ to $5^{\circ}$. The $C_{L} / C_{D}$ magnitude reach its maximum value (known as $C_{L} / C_{D \max }$ ) at $C_{L}=-0.056$ to 0.222 or which $\alpha$ between $2^{\circ}$ to $5^{\circ}$. However, as the $C_{L}$ increase further (or $\alpha>5^{\circ}$ ), the $C_{L} / C_{D}$ performances for each design is gradually drop towards the stall condition at $C_{L}$ between 1.067 to 1.246 (or $\alpha$ between $25^{\circ}$ to $32^{\circ}$ ). Based on the overall $C_{L} / C_{D}$ performance, the result clearly shows that the Glider paper has the lowest $C_{L} / C_{D}$ magnitude in almost every $C_{L}$ cases. The design averagely produced at least $5.69 \%$ 
lower $C_{L} / C_{D}$ magnitude compared to the other design. On the other hand, Wide Stunt paper plane has averagely produced at least $1.82 \%$ better $C_{L} / C_{D}$ magnitude compared to the other design.

Comparative analysis was also conducted by focusing on the difference in $C_{L} / C_{D \max }$ magnitude among the paper plane. The result clearly shows that Wide Stunt paper plane induced the best $C_{L} / C_{D \max }$ magnitude among the paper plane at $C_{L} / C_{D \max }=6.32$. This condition happens at $C_{L}=0.108$ and relatively at $\alpha=2^{\circ}$. This is followed by Stunt paper plane at $C_{L} / C_{D \max }=5.94$ which relatively occurred at $C_{L}=0.138$ and $\alpha=2^{\circ}$. The Glider paper plane induced the lowest $C_{L} / C_{D \max }$ magnitude among the paper plane at $C_{L} / C_{D \max }=5.45$. This is happening at $C_{L}=0.269$ and $\alpha=5^{\circ}$. Based on these results, it clearly shows that Wide Stunt paper plane induced at least $6.4 \%$ better $C_{L} / C_{D \max }$ magnitude compared to the other paper plane design. In fact, the $C_{L} / C_{D \text { max }}$ magnitude for Wide Stunt paper plane is also produced at $3^{\circ}$ earlier than the Glider paper plane. This means that optimal aerodynamic condition for Wide Stunt paper can be easily achieved with very minimal tilting $\alpha$ angle. These promising results is due to better $C_{D}$ performance found on the Wide Stunt paper. Lower $C_{D}$ value (at $\alpha$ region below $15^{\circ}$ ) and better $C_{D \min }$ magnitude has benevolently delayed the drag to overwhelm the lift distribution on the Wide Stunt paper plane design. On the other hand, despite of huge advantage in lift distributions, the the significant drag generation on the Glider plane design has overwhelm its lift performances which leads into lower $C_{L} / C_{D}$ performances.

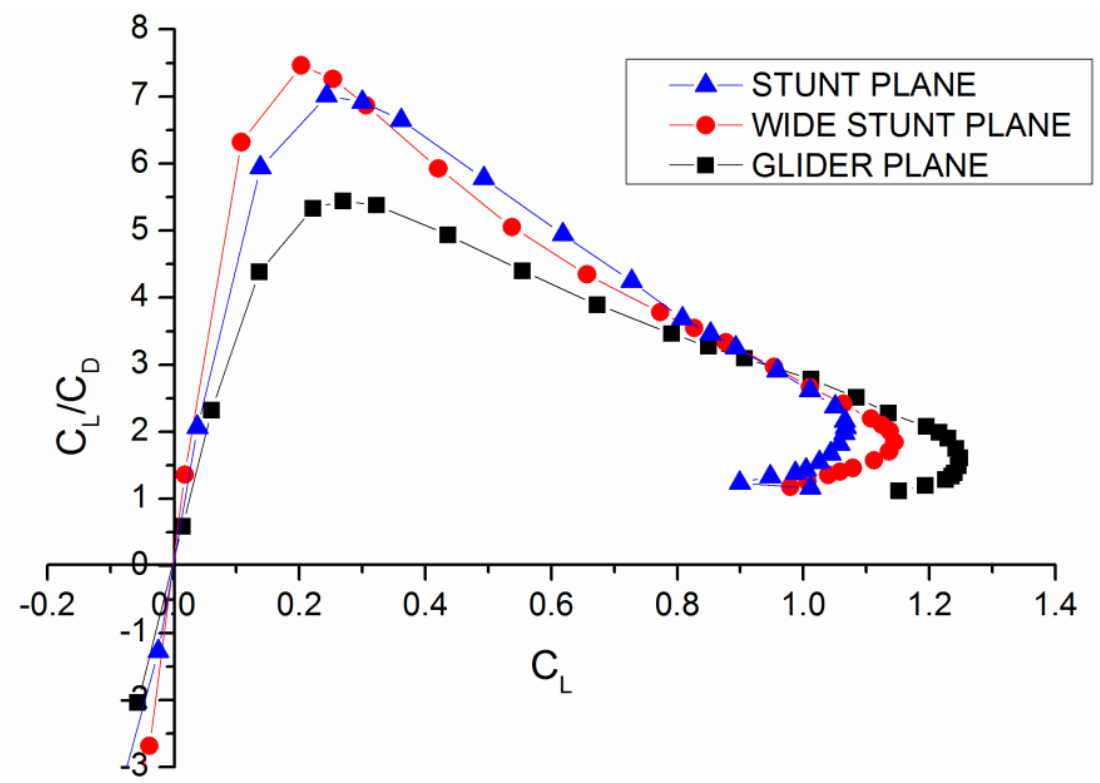

Fig. 8. $C_{L} / C_{D}$ performance for Glider, Stunt Plane and Wide Stunt Glider paper plane

\section{Conclusions}

In this work the aerodynamic analysis on selected paper plane designs known as Glider, Wide Stunt Glider and Stunt plane was carried out. Based on CFD methods the results show that the Glider paper plane has surprisingly produces promising performances in $C_{L}$. Even at low aspect ratio magnitude ( $A R=2.81$ ), the Glider paper plane managed to produce better performances in the Glider paper plane managed to produce better $C_{L}$ (at $\alpha$ cases over $15^{\circ}$ ), $\alpha_{\text {stall }}$, wider $\alpha$ envelope and higher $C_{L \max }$ magnitude compared to the other paper plane design. Surprisingly, its promising advantages does not continue in $C_{D}$ performances in which the Glider paper plane has at least $14.3 \%$ larger $C_{D}$ magnitude compared to the other plane design at certain $\alpha$ region. Instead, The Wide Stunt has promisingly produced better $C_{D}$ distribution based on its lower $C_{D}$ value (at $\alpha$ region below $15^{\circ}$ ) and 
lower $C_{D \min }$ magnitude compared to the other plane design. Based on $C_{L} / C_{D}$ performance, Wide Stunt paper plane has clearly produced better $C_{L} / C_{D}$ and $C_{L} / C_{D \max }$ magnitudes compared to the other design. Wide Stunt paper plane induced at least $6.4 \%$ better $C_{L} / C_{D \max }$ magnitude compared to the other paper plane design. In fact, the $C_{L} / C_{D \max }$ magnitude for Wide Stunt paper plane is produced at $3^{\circ}$ earlier than the Glider paper plane. Based on these results, one can conclude that Wide Stunt paper plane shows promising advantages in producing better aerodynamic efficiency at lower $\alpha$ angle. Such advantages are very crucial for the paper plane especially during hovering operation, take-off, and landing manoeuvre.

\section{Acknowledgement}

The authors acknowledge technical and financial support from Universiti Teknologi MARA and the Government of Malaysia via the sponsorship by the Malaysia Ministry of Higher Education's Fundamental Research Grant Scheme (FRGS) (600-RMI/FRGS 5/3 (173/2019)).

\section{References}

[1] Adams, Christina. "Paper Plane." Education 92, no. 8 (2011): 20.

[2] Klaptocz, Adam, and Jean-Daniel Nicoud. "Technology and fabrication of ultralight micro-aerial vehicles." In Flying Insects and Robots, pp. 299-316. Springer, Berlin, Heidelberg, 2009. https://doi.org/10.1007/978-3-540-89393621

[3] Witushynsky, Tim C. "Experimental Investigation Into The Aerodynamics Of Small Air Vehicles With Thin Flexible Wings." PhD diss., Case Western Reserve University, 2008.

[4] Gresham, Nicholas T., Zhijin Wang, and Ismet Gursul. "Low Reynolds number aerodynamics of free-to-roll low aspect ratio wings." Experiments in Fluids 49, no. 1 (2010): 11-25. https://doi.org/10.1007/s00348-009-0726-2

[5] Pounds, P. "Paper plane: Towards disposable low-cost folded cellulose-substrate UAVs." In Australasian Conference on Robotics and Automation, pp. 3-5. 2012.

[6] Pounds, Paul EI, and Surya PN Singh. "Integrated electro-aeromechanical structures for low-cost, self-deploying environment sensors and disposable UAVs." In 2013 IEEE International Conference on Robotics and Automation, pp. 4459-4466. IEEE, 2013. https://doi.org/10.1109/ICRA.2013.6631210

[7] Chamberlain, Daven Christopher. "Paper." In The Oxford Companion to the Book, pp. 79-88. 2010.

[8] Suhaimi, S., H. Yusoff, N. Iswadi, Sh Mohd Firdaus, S. Shuib, M. K. Abdullah, and A. A. Rashid. "Natural Rubber Latex Fabrication for Bio-Inspired Flapping Wing Skin Based on Bat Wings." Journal of Mechanical Engineering and Automation 6, no. 6 (2016): 151-155.

[9] Ismail, N. I., A. H. Zulkifli, M. Z. Abdullah, M. Hisyam Basri, and Norazharuddin Shah Abdullah. "Computational aerodynamic analysis on perimeter reinforced (PR)-compliant wing." Chinese Journal of Aeronautics 26, no. 5 (2013): 1093-1105. https://doi.org/10.1016/i.cja.2013.09.001

[10] Turner, Nicholas, Bill Goodwine, and Mihir Sen. "A review of origami applications in mechanical engineering." Proceedings of the Institution of Mechanical Engineers, Part C: Journal of Mechanical Engineering Science 230, no. 14 (2016): 2345-2362. https://doi.org/10.1177/0954406215597713

[11] Toys, Tailor. PowerUp 3.0 Smartphone Controlled Paper Airplane :User Guide, 2014. 